Esta revista forma parte del acervo de la Biblioteca Jurídica Virtual del Instituto de Investigaciones Jurídicas de la UNAM

\title{
La regulación internacional de la inversión extranjera directa durante la administración de Donald Trump. Una visión histórica
}

\author{
The International Regulation of Foreign Direct Investment \\ During the Administration of Donald Trump. A Historical Vision \\ La regulation international de l'investissement etranger \\ direct au cours de l'administration du president Donald Trump. \\ Une perspective historique
}

\section{Adelina Quintero Sánchez*}

SUMARIO: I. Introducción. II. El papel de Estados Unidos en la evolución de la regulación internacional de la inversión extranjera. III. Marco jurídico de Estados Unidos para la inversión extranjera. IV. El modelo estadounidense de BIT. V. Del TLCAN al UMSCA. VI. Conclusiones. VII. Bibliografía.

* Profesora de tiempo completo, asociada "C", en la Facultad de Estudios Superiores Acatlán, UNAM, en el área económica de la carrera de Relaciones Internacionales; miembro del Sistema Nacional de Investigadores y autora de diversos artículos y capítulos de libros.

Artículo recibido el 15 de enero de 2018 Aprobado para publicación el 3 de octubre de 2019 
RESUMEN: La llegada de Donald Trump a la presidencia de EE UU implicó muchos cambios en diversas áreas, no obstante, con respecto a la regulación de la inversión extranjera esta siguió el mismo objetivo y lineamientos que la han caracterizado desde que definió su modelo de Tratado Bilateral de Inversiones, décadas atrás. La prioridad central de la regulación de la inversión extranjera es la protección de sus empresas en los países donde se instalan, principalmente, cuando estos son subdesarrollados.

Palabras clave: inversión extranjera, Estados Unidos, Trump, empresas transnacionales.

ABSTRACT: The arrival of Donald Trump to the presidency of the USA involved many changes in different areas, however with respect to the regulation of foreign investment this followed the same objective and guidelines that have characterized it since it defined its model of bilateral investment treaty, decades ago. The central priority of the regulation of foreign investment is the protection of their companies in the countries where they are installed, mainly when they are underdeveloped.

Key words: foreign investment, United States, Trump, transnational companies.

RÉSUMÉ: L'arrivée de Donald Trump à la présidence des États-Unis a entraîné des changements copieux à different secteurs, cependant la régulation de l'investissement étranger a suivi la cible et les directrices que lui caractérisent depuis avoir établi son modèle de traité bilatéral d'investissement, il y a quelque décennies. La priorité axiale de la régulation de l'investissement étranger, c'est la protection de ses entreprises dans les Pays où elles s'installent, principalement, quand il s'agit de pays en développement.

Mots-clés: investissement étranger, États-Unis, Trump, Entreprises transnationales. 
Esta revista forma parte del acervo de la Biblioteca Jurídica Virtual del Instituto de Investigaciones Jurídicas de la UNAM

Estados Unidos (EE UU) hasta hoy en día, es el país con más presencia en los flujos de inversión extranjera directa (IED), tanto como emisor como receptor, al tiempo que es la casa matriz del mayor número de empresas transnacionales (ET), las cuales constituyen los principales vehículos de la inversión. Esta situación, en consonancia con su estatus de potencia hegemónica y arquitecto del andamiaje institucional que conforma el sistema de Naciones Unidas explica su papel como artífice principal del régimen internacional para la regulación de la inversión extranjera, que se construye, esencialmente, a través de dos vías: acuerdos bilaterales de inversión y capítulos de inversión dentro de los acuerdos de libre comercio. La principal característica de esta regulación es proteger a la inversión estadounidense de prácticas nocivas por parte de los países receptores, garantizar las mejores condiciones para su establecimiento, desarrollo y funcionamiento, así como ofrecerle opciones alternas para dirimir sus controversias, y que éstas no se remitan a los tribunales nacionales de los Estados en las que operan. Es preciso enfatizar que dicho régimen se enfoca más en regular la inversión extranjera en países en desarrollo, que en sus contrapartes industrializadas.

De ahí que, se plantea como hipótesis de este trabajo que más allá de la retórica discursiva y propagandística de la administración Trump y aunque se hayan dado varias acciones contrarias a seguir con las mismas políticas en materia de regulación internacional de la inversión extranjera, esta regulación no ha sufrido cambios radicales, más bien se le ha dado continuidad en consonancia con la doctrina de protección y promoción de las inversiones, la cual ha adquirido tintes más neoproteccionistas. Mientras que el objetivo es analizar la regulación internacional que se ha desprendido de los acuerdos firmados durante la administración de Donald Trump a la luz de una revisión histórica para determinar el papel de Estados Unidos dentro del régimen internacional para regular la inversión extranjera.

Finalmente, se debe señalar que la metodología utilizada es deductiva-argumentativa, con base en la revisión de los acuerdos en materia de inversión signados por Estados Unidos, informes de organismos internacionales e investigaciones especializadas en la materia. 
Esta revista forma parte del acervo de la Biblioteca Jurídica Virtual del Instituto de Investigaciones Jurídicas de la UNAM

\section{EL PAPEL DE ESTADOS UNIDOS EN LA EVOLUCIÓN DE LA REGULACIÓN} INTERNACIONAL DE LA INVERSIÓN EXTRANJERA

Desde que EE UU obtuvo su independencia, comenzó a incrementar su comercio e inversión en el mundo, echando mano, en principio, de los territorios más accesibles como América Latina, donde la visión era ir intercambiando materias primas por maquinaria y bienes manufacturados, a la vez que invertían en cobre, hierro, plomo y minas de plata, para sustentar su desarrollo industrial. ${ }^{1}$

Es imprescindible destacar que en el período que va desde 1914 hasta 1945, cuando EE UU ya había asimilado exitosamente la primera etapa de la Revolución Industrial, iniciada en Inglaterra, su meta fue ampliar su poder económico y desplegar su inversión extranjera, esencialmente en Latinoamérica y algunas partes de Europa del Este. ${ }^{2}$

Estados Unidos emerge como la primera potencia industrial del mundo después de la Primera Guerra Mundial (PGM), impulsado por el desarrollo de sus industrias pesadas e incursiona, como nunca antes, en empresas con base científica y tecnológica, como la industria eléctrica, la química, la petrolera y la de telecomunicaciones; es decir, la expresión de la segunda revolución industrial. Asimismo, nace la corporación y se implementa el fordismo como sistema de producción en masa con base en el desarrollo de las máquinas-herramienta y las partes intercambiables. Entonces hay una sobreproducción y se visualizan los países de forma geoestrategia, dónde se pueden vender los productos, de los cuales se pueden obtener nuevas tecnologías y los que pueden actuar como proveedores de materias primas básicas, como el petróleo.

Antes de la Primera Guerra Mundial, Estados Unidos había tenido, hacia sus inversiones en países en desarrollo, una política reactiva, que se apoyaba en la diplomacia del dólar e intervenciones militares para proteger

1 Todavía en el siglo XIX cuando Estados Unidos aún estaba en proceso de desarrollo industrial y Gran Bretaña conservaba una presencia muy grande en todo el continente, sólo en algunos mercados como el mexicano y cubano los comerciantes e inversionistas estadounidenses obtuvieron una posición dominante, mientras Gran Bretaña conservaba su estatus de potencia comercial dominante, particularmente en manufacturas que daba a cambio de materias primas como azúcar, algodón, carne y trigo. O’Brien, Thomas, The Century of U.S. Capitalism in Latin America, Nuevo Mexico, University of New Mexico Press, 1999, pp. 4-6.

2 Dávila Aldas, Francisco, “América Latina y la globalización”, Revista de Relaciones Internacionales, México, núms. 101 y 102, mayo-diciembre de 2008, pp. 43 y 44. 
los intereses de sus empresarios; sin embargo, ya con las corporaciones, se privilegió la búsqueda de protección legal para las patentes y derechos de propiedad intelectual a fin de no sólo proteger su propiedad, sino también sus mercados y su tecnología.

La gran depresión de los años veinte fue un impasse en el avance del comercio y la inversión extranjera estadounidense, sin embargo, cuando esta se terminó se reemprendió la expansión con una agresiva agenda que buscaba, por una parte, allegarse de minerales y productos agrícolasy por otra, seguir absorbiendo nuevas tecnologías e incrementar su base industrial y comercial.

Al finalizar la Segunda Guerra Mundial (SGM), las empresas estadounidenses, principalmente de bienes de consumo, experimentaron su boom en el mundo y observaron la oportunidad para volver a expandirse en todos los mercados y colocar sus productos en el exterior, desde los artículos de lujo hasta los básicos, tales como Coca-Cola y Chevrolet. No obstante, en algunos países como los latinoamericanos y los socialistas, dada la coyuntura histórica, tropezaron con algunos obstáculos para establecerse, sobre todo de orden político e ideológico. ${ }^{3}$

La recién surgida potencia hegemónica (EE UU) coordinó la creación de todo un andamiaje institucional para reestructurar el sistema internacional de posguerra y crea diferentes organizaciones internacionales para regular los temas nodales del quehacer internacional en torno a Naciones Unidas, como el Fondo Monetario Internacional (FMI) y el Banco Internacional para la Reconstrucción y el Fomento (BIRF), que después sería parte del Grupo del Banco Mundial, ${ }^{4}$ para el sistema financiero y la reconstrucción. Sin embargo, entre los organismos establecidos después de la SGM, para regular las relaciones internacionales, no se creó ninguno para la IE (inversión extranjera); por lo que estos tópicos de forma indirecta se incluyeron en otro organismo. ${ }^{5}$

Así, la Carta de la Habana de 1948, diseñada para establecer la Organización Internacional de Comercio (OIC), constituye el primer intento

3 O’Brien, Thomas, op. cit., p. xiii.

4 Dentro del Grupo del Banco Mundial se fueron creando entidades relacionadas con la inversión, como la Agencia Financiera Internacional, el Organismo Multilateral de Garantía de Inversiones y el Centro Internacional de Arreglo de Diferencias relativas a Inversiones.

5 Tolentino, Paz Estrella, "Transnational Rules for Transnational Corporations. What Next?", en Michie, Jonathan y Grieve-Smith, John (eds.), Global Instability:The Political Economy of World Governance, Londres, Universidad de Londres, 1999, p. 32. 
DOI: http://dx_doi.org/10.22201/iij_24.487872e_2020.20.14490

por crear, a nivel multilateral, un marco de regulación para la inversión extranjera. Aunque en la Carta imperaba el contenido comercial, EE UU propuso incluir artículos con cierta protección para la IE, que lo favorecerían directamente al ser el principal acreedor de la época, visualizando que con ello podría extender sus intereses en materia de inversión, enlazándolos con el comercio, ya que en ese momento era poca la disposición a firmar acuerdos bilaterales por parte de los países en desarrollo. ${ }^{6}$ Esto constituye el primer intento por crear un régimen multilateral para la protección a la IE, además de su táctica de amalgamarlo con el comercio.

El borrador sobre la protección a la inversión establecía, entre otras cosas, que los países debían incentivar las inversiones extranjeras a través de abrir sectores restringidos a los nacionales, a la par de no discriminarlas y ofrecerles protección y seguridad a largo plazo, incluyendo la garantía de no expropiar o nacionalizar los activos de una empresa extranjera, salvo por razones justas y razonables. De igual manera, se exhortaba a los miembros interesados en atraer inversiones a firmar acuerdos bilaterales o multilaterales en la materia. ${ }^{7}$ Es menester señalar que, éstas disposiciones no fructificaron como parte de la OIC, puesto que la organización nunca se creó, y lo único que se ratificó fue el Acuerdo General sobre Aranceles Aduaneros y Comercio (GATT, por sus siglas en inglés), que se concentró en la desarancelización, dejando el tema de inversión para futuras negociaciones.

De forma simultánea EE UU avanzó en la regulación para la inversión extranjera en el orden internacional al firmar acuerdos bilaterales que incluyeran algunas prerrogativas para la IE, así desde 1945 empezó a negociar una serie de acuerdos de amistad, comercio y navegación, creando una nueva generación de los mismos, ${ }^{8}$ que si bien se orientaban al comercio, ya incluían provisiones para proteger la propiedad en territorio extranjero; es decir, la IE, aunque no con ese nombre, en conformidad con las normas de

6 Gutiérrez-Haces, Teresa, "Inversión extranjera directa en el TLCAN", Economía, México, vol. 1, núm. 3, 2004, p. 35.

7 Organización Internacional de Comercio, “Carta de la Habana”, artículo 12, 1948.

8 El contenido de estos tratados dista mucho de lo estipulado en la primera generación de los mismos, dedicados exclusivamente al tránsito de mercancías, como el firmado con México en 1831. Fukunari, Kimura, Issues and Options for the Multilateral, Regional, and Bilateral Trade Policies of the United States and Japan, Conferencia en la Universidad de Michigan (Ann Arbor), 5 y 6 de octubre de 2000 . 
derecho internacional. ${ }^{9}$ Puede decirse que son un antecedente no sólo de los tratados de libre comercio, sino de los propios acuerdos bilaterales para la inversión (BIT, por sus siglas en inglés), al ser acuerdos previos que incluyen garantías para la protección de la IE y de los inversionistas en consonancia con el comercio y la navegación.

Los países en desarrollo, por su parte, adoptaron el enfoque de "soberanía permanente sobre riquezas y recursos naturales” emanado de Naciones Unidas, que enfatizaba el derecho de los pueblos a disponer de sus recursos naturales y expropiar en caso de considerarlo preciso, sin importar que contravinieran disposiciones emanadas de otros acuerdos. Los países exportadores de capital, encabezados por Estados Unidos, como respuesta, sentaron las bases de la doctrina "de la promoción y protección de las inversiones”, que es la que continúa prevaleciendo hasta hoy en día. Ésta se empezó a debatir en el seno de la ahora Organización de Cooperación y Desarrollo Económico (OCDE), con la iniciativa para la Convención Multilateral Abs-Shawcross de 1959, la cual, aunque nunca se firmó, sí sirvió de fuente de inspiración para el contenido de los primeros BIT. ${ }^{10}$

Después de que en 1959 se celebrara el primer acuerdo bilateral para la inversión entre Alemania y Pakistán, muchos países los siguieron en la firma de este tipo de acuerdos en las dos décadas posteriores. En el caso de EE UU, no se remitió a la firma BIT, sino que, comenzó a incidir en los contenidos de los mismos.

El modelo prevaleciente del BIT, de acuerdo con la doctrina de promoción y protección de las inversiones, hace alusión al círculo virtuoso de la inversión, el que establece que las inversiones son fuente por excelencia de empleos, tecnología, competencia y capital, por lo que, los países receptores deben ofrecer la adecuada protección por medio de un marco jurídico que les brinde certidumbre. Un aspecto toral es la búsqueda de mecanismos que permitan superar las legislaciones y tribunales nacionales, considerados arbitrarios y parciales, a los que debían someterse los inversionistas extranjeros en caso de controversia. La propuesta para resolver este recoveco era crear una instancia supranacional donde se dirimieran las

9 Vandevelde, Kenneth, The First Bilateral Investment Treaties. U.S. Postwar Friendship, Commerce and Navigation Treaties, EUA, Oxford University Press, 2017, pp. 57 y 58.

10 Gutiérrez-Haces, Teresa y Quintero, Adelina, "Hacia la construcción de un régimen internacional de protección a la inversión extranjera”, Norteamérica, México, vol. 11, núm. 2, 2016 , pp. 120 y 121. 
Esta revista forma parte del acervo de la Biblioteca Jurídica Virtual del Instituto de Investigaciones Jurídicas de la UNAM

DOI: http://dx.doil.org/10.22201/iij.24487872e_2020.20.14490

controversias y los inversionistas pudieran contar con representación propia frente al país receptor. ${ }^{11}$

A nivel internacional, los países desarrollados, esencialmente Estados Unidos y los de Europa Occidental, implementaron, a través de la costumbre internacional, un estándar mínimo de trato, el cual les otorgaba determinadas prerrogativas y garantías a los inversionistas extranjeros en el territorio del país receptor. Uno de los lineamientos básicos era la restricción de las expropiaciones y la adecuada compensación en caso de proceder. ${ }^{12}$ No obstante, gran parte de los países en desarrollo y los socialistas se oponían a este trato mínimo, bajo el argumento de que contravenía su soberanía nacional.

Los BIT rápidamente se convirtieron en acuerdos atípicos, ya que a diferencia de otros tratados bilaterales de la época que se daban entre partes con un mismo nivel de desarrollo, éstos en su mayoría incluían a una parte desarrollada y otra en desarrollo, así también transitaron, principalmente los firmados por Estados Unidos, de ser instrumentos que protegían y promovían la inversión a convenios que sólo promueven la IE de forma indirecta, dado que su único objetivo es protegerla. ${ }^{13}$

Entre 1959 y 1969, sólo se firmaron 72 BIT, pero estos estuvieron determinados por los intereses de los países desarrollados y establecieron los contenidos clave para este tipo de acuerdos, aún vigentes, tales como las cláusulas de trato nacional, de nación más favorecida, la restricción de expropiación, la garantía de libre transferencia y la opción arbitral para solución de controversias entre Estados, y entre inversionista-Estado en casos excepcionales. ${ }^{14}$

El nacimiento del Centro Internacional para el Arreglo de Disputas sobre Inversiones (CIADI), como parte del Grupo del Banco Mundial, a iniciativa de Estados Unidos, fue un avance en el mismo sentido. El Centro se creó para administrar el arbitraje y las controversias entre inversionistas y Estados, constituyendo de esta manera una nueva forma de arbitraje internacional, en la que una de las partes es del orden público y la otra del

11 Nassar Guier, Edgar, “La garantía internacional de inversiones”, Relaciones Internacionales, Costa Rica, 2a. época, 1994, p. 17.

12 UNCTAD, International Investment Rule-Making: Stocktaking, Challenges and the Way Forward, Nueva York-Ginebra, ONU, 2008, pp. 10 y 11.

13 Ibidem, p. 12.

14 Ibidem, p. 13. 
privado; práctica que pronto se volvió recurrente entre los BIT. Asimismo, desde 1960 se trató de abrir un foro similar en el seno de la Corte Permanente de Arbitraje, la cual fue creada por la Conferencia de Paz de la Haya en 1899 , pero éste no fructificó. ${ }^{15}$

La creación del CIADI fue un paso decisivo para los países desarrollados, dado que materializaba una de sus búsquedas históricas para proteger a sus empresas y a sus inversiones. No obstante, resultaba insuficiente, ya que hacía falta producir un incentivo para que los países en desarrollo aceptaran y decidieran acudir a este mecanismo de solución de controversias. Posteriormente, en los años setenta se introduce el concepto de "garantía de inversiones”, es decir, un seguro contra el riesgo político, que se refiere a cualquier acción o eventualidad que ponga en riesgo las inversiones extranjeras. De ahí que surjan distintas instancias para la garantía de las inversiones, como la Overseas Private Investment Corporation (OPIC) en Estados Unidos, y la Agencia Multilateral para la Protección y Garantía de Inversiones (MIGA por sus siglas en inglés), perteneciente al Grupo del Banco Mundial. ${ }^{16}$

Aunque el enfoque de "soberanía permanente de los países en desarrollo”, alcanzó su máximo esplendor al incorporarse, en 1974, a la Carta de Derechos y Deberes Económicos de los Estados, parte de la iniciativa del denominado Nuevo Orden Económico Internacional (NOEI), en el seno de Naciones Unidas, pronto fue opacado, dada la coyuntura internacional marcada por la crisis económica internacional que se superaría hasta finales de los ochenta y junto con el término de la Guerra Fría, que derivarían en la expansión del capitalismo a nivel global.

Las propuestas del NOEI fueron desplazadas por nuevas iniciativas de tratados bilaterales de inversión, y en el caso de EE UU, este inauguró su propio modelo de BIT. La creación del programa estadounidense para BIT es trascendental, pues revoluciona el contenido típico de estos acuerdos. El modelo estadounidense agrega nuevas prerrogativas para la protección de

15 Véase Álvarez Ávila, Gabriela, “Las características del arbitraje del CIADI”, en Velásquez Elizarrarás, Juan Carlos (comp.), El derecho internacional público y privado a través de los debates teóricos actuales en las Universidades de México y el extranjero, México, UNAM, 2005.

16 Véanse Contreras García, Joaquín, “Algunas consideraciones sobre la protección a la IED a la luz del derecho internacional privado”, Jurídica, México, núm. 24, 1995; Checkley, Juan Carlos et al., "La inversión extranjera y los Convenios MIGA y OPIC", Revista del Foro, Lima, año XXIX, enero-junio de 1991. 
sus empresas, tales como la protección al preestablecimiento; convierte en regla el mecanismo de solución de controversias inversionista-Estado, que se utilizaba excepcionalmente; pasa de restringir algunos requisitos de desempeño a prohibirlos en su mayoría, además de eliminar cláusulas relacionadas directamente con la promoción para la inversión, como transferencia de tecnología, cooperación científica y técnica, entre otras; haciendo así que éstos acuerdos se carguen más hacia la protección que hacia la promoción de la inversión extranjera. ${ }^{17}$

Posteriormente, Estados Unidos da un paso más allá al incluir el contenido de su programa de BIT en los acuerdos de libre comercio, donde el Tratado de Libre Comercio de América del Norte (TLCAN) es el que inaugura esta tendencia. ElTLCAN es un tratado de comercio que incluye un capítulo extenso sobre inversión, con normas de protección muy similares a las contenidas en los BIT firmados por EE UU, aunque más extenso y detallado en algunos aspectos. ${ }^{18}$ Éste tratado remplazó al Acuerdo de Libre Comercio entre Canadá y Estados Unidos (ALCCEU), que ya contenía un capítulo dedicado a la inversión, pero era más escueto, entre dos países con un nivel de desarrollo económico similar y menor nivel de exigencia, marcando un parteaguas en la historia de los TLC's al incluir la fórmula comercio-inversión.

A partir del nuevo milenio se incursionó en una nueva etapa de la regulación internacional a la IE, puesto que el consenso alcanzado sobre el modelo neoliberal de protección a la inversión se puso en entredicho, consecuencia de la evaluación de los resultados obtenidos de las políticas de este corte aplicadas, que han sido por debajo de las expectativas en muchos casos; llevando a que los elementos básicos de las premisas de la protección y promoción de las inversiones sean reexaminados, y en algunos casos modificados. ${ }^{19}$ No obstante, en EE UU a partir de que se sustituyó la ley

17 El BIT entre Estado Unidos y Bolivia fue de los primeros en prohibir los requisitos de desempeño, véase UNCTAD, op. cit., p. 13.

18 A partir del TLCAN se firmaron otros acuerdos de libre comercio que siguieron la tendencia de incluir temas relacionados como IE, entre ellos destaca el Acuerdo Marco de Inversión para la Asociación de Naciones del Sudeste Asiático (ANSEA) de 1998, el Tratado de Libre Comercio entre Panamá y Singapur de 2006 y el Acuerdo de Asociación Económica entre Nueva Zelanda y Tailandia de 2005.

19 Sauvant, Karl P. y Ortino, Federico, Improving the International Investment Law and Policy Regime: Options for the Future, London, King's College, London, 2017, pp. 33-36. 
conocida como Fast Track en 2002 por el Acta de Autoridad de Promoción Comercial (TPA, por sus siglas en inglés), el Congreso retomó la discusión sobre la protección a la IE en diversos foros internacionales y ha tratado de insertar su modelo de regulación. ${ }^{20}$

Así, el modelo de BIT, o mejor dicho, el modelo de regulación internacional para la inversión extranjera estadounidense ha ido evolucionado y sofisticándose, al tiempo que se ha vuelto multifacético y se ha insertado tanto en los capítulos dentro de los TLC como en distintos tipos de acuerdos regionales y con grupos de países.

A nivel multilateral, la aceptación de las normas en materia de inversión promovidas por Estados Unidos ha sufrido varios reveses, como en las negociaciones del Área de Libre Comercio de las Américas, en las negociaciones de los denominados temas de Singapur en la OMC y en el intento fallido del Acuerdo Multilateral de Inversiones, en el seno de la OCDE. A pesar de esto se sigue buscando su inclusión y expansión en nuevos acuerdos y nuevas áreas, como se intentó en la administración Obama a través del Acuerdo de Asociación Transpacífico (TPP, por sus siglas en inglés), y el recientemente firmado acuerdo entre Estados Unidos, México y Canadá (UMSCA, por sus siglas en inglés).

\section{MARCO JURÍDICO DE ESTADOS UNIDOS PARA LA INVERSIÓN EXTRANJERA}

Estados Unidos continúa siendo el principal inversor en el mundo, de acuerdo con la UNCTAD, en 2017 invirtió en el exterior una suma de 342

20 En 1970, en EE UU se crea el Trade Act con el fin de elevar los aranceles y protección comercial para varios productos. Sin embargo, para asegurarse que el Congreso no limitara la autoridad del Ejecutivo se firmó el Trade Act de 1974 que autorizaba al presidente a reducir barreras arancelarias y neoproteccionistas. Empero el Congreso no deseaba otorgar una carta blanca al presidente, por lo que nació el sistema de fast track, temporal y renovable. Este procedimiento le permite negociar al representante del Ejecutivo, bajo un mandato especial ("la vía rápida”), acuerdos comerciales que no pueden ser modificados posteriormente por el Congreso, quien sólo puede aprobar o rechazar el acuerdo en su totalidad. Posteriormente, en 2002, durante la segunda administración de Bush padre, cambia de nombre a TPA, aunque el contenido se mantiene, básicamente para buscar firmar más acuerdos comerciales y de inversión. Véase Roett, Riordan, "La política de los Estados Unidos frente a la integración continental”, Contribuciones, año XVIII, núm. 3, julio-septiembre de 2001. 
mil millones de dólares, mientras que recibió inversiones extranjeras por 275 mil millones de dólares. ${ }^{21}$ Asimismo, Estados Unidos aún es la casa matriz del mayor número de empresas transnacionales de mayor presencia en el mundo, de acuerdo al ranking de las 2,000 principales empresas más globales, elaborado por Forbes, dicho país cuenta con 560, ocupando el primer puesto, seguido por China con 291..$^{22}$ De acuerdo con la UNCTAD, dentro del top 100 de empresas transnacionales (ET) 2017, Estados Unidos sigue encabezando la lista con $20 .^{23}$

Como se visualizó en el apartado anterior, desde que EE UU se consolidó como potencia hegemónica al término de la SGM, se posicionó tanto en los flujos de capital como en las regulaciones internacionales en torno a los mismos. Las ET estadounidenses tenían ya la capacidad y la necesidad de expandirse más allá de sus fronteras, por lo que aprovecharon los cambios acaecidos en las diferentes regiones para activar la dinámica capitalista a nivel global. Este despliegue estadounidense se dio, tanto para insertarse en Europa, Asia y África como, por supuesto, en América Latina. Así, el gobierno, en apoyo a esta estrategia, ha avanzado en la firma de BIT y TLC comprensivos que incluyen un apartado sobre IE, en conjunción con otras acciones para ofrecer las mejores condiciones a sus ET. Este objetivo no ha cambiado a raíz de que lleguen nuevas administraciones, ya sean demócratas o republicanas y tampoco ha sido el caso con el gobierno de Donald Trump, a pesar de los escándalos que han caracterizado lo que va de su mandato.

Aun en la coyuntura actual, donde priman los temas de seguridad en la agenda de política exterior estadounidense, son vitales los intereses comerciales, siguiendo aún lo establecido en la Trade Act de 2002, la cual marca que el comercio internacional es vital para la seguridad nacional de EE UU al ser un elemento crítico para su crecimiento económico, su poderío y su liderazgo en el mundo, considerando además, que su seguridad nacional depende de su seguridad económica, que a su vez está cimentada en las oportunidades de inversión que tenga su creciente base industrial en sectores clave en el exterior; es decir, a través de sus ET, tales como tecno-

21 UNCTAD, World Investment Report 2018, Nueva York-Ginebra, ONU, 2018, pp. 61 y 184.

22 “Global 2000: Las empresas más grandes del mundo de 2018”, Forbes, México, 7 de enero de 2018. Disponible en: https://www.forbes.com.mx/global-2000-las-empresas-mas-grandesdel-mundo-de-2018/.

23 UNCTAD, World Investment Report 2018, cit., pp. 28 y 29. 
logía de la información, telecomunicaciones y otras tecnologías de vanguardia, industrias básicas, bienes de capital, servicios, agricultura y propiedad intelectual. En resumen, sostiene que el comercio y la IE crearán nuevas oportunidades para EE UU y preservarán su fuerza inconmensurable en los asuntos económicos, políticos y militares. La Administración de Comercio Internacional (ITA, por sus siglas en inglés), subraya que su misión es “coadyuvar a crear oportunidades económicas para los negocios y trabajadores americanos a través de la inversión y del comercio; que son las bases para promover la prosperidad y un mundo mejor". ${ }^{24}$

En el discurso oficial para el gobierno estadounidense, las normas internacionales para la protección a la inversión extranjera derivadas de sus diferentes instrumentos, tienen como finalidad proteger los intereses de sus inversionistas en el extranjero, desarrollar políticas orientadas al mercado en los países socios y promover las exportaciones estadounidenses. ${ }^{25}$ De acuerdo al gobierno de EE UU las ET requieren, para desplegarse en un determinado país, que todos sus sectores estén abiertos a la inversión extranjera, así como una adecuada infraestructura, burocracias flexibles, condiciones macroeconómicas estables, acceso a los recursos nacionales y gobernanza. Estas exigencias evidencian la búsqueda de las condiciones más idóneas para el despliegue de sus empresas transnacionales. ${ }^{26}$ Para ello el gobierno se compromete a otorgar a las inversiones en el extranjero seis beneficios básicos, que se insertan en el clausulado de los acuerdos en materia de inversión, que son:

- Trato nacional y de nación más favorecida (NMF) para sus inversiones;

- Claridad y limitación en las expropiaciones;

- Garantía de libre transferencia de fondos por parte de los inversionistas;

- Limite a la habilidad de los gobiernos receptores de imponer requisitos de desempeño o condiciones para el establecimiento o mantenimiento de la inversión;

24 International Trade Administration, "Promoting Trade and Investment", 18 de abril de 2017. Disponible en: http: / /trade.gov/promotingtrade/index.asp.

25 Office of the United States Trade Representative, "Bilateral Investment Treaties", 8 de mayo de 2017. Disponible en: http: / / www.ustr.gov/trade-agreements/bilateral-investment-treaties.

26 Barefoot, Kevin B. y Raymond, J. Mataloni Jr., "U.S. Multinational Companies”, U.S. Bureau of Economic Analysis, Operations of Multinational Companies. U.S. Direct Investment Abroad, p. 74. 
- Evitar se restrinja la movilidad del personal gerencial de la inversión o se solicite que parte de la planta productiva tenga una determinada nacionalidad, y

- Ofrecer un mecanismo de solución de controversias entre un inversionista y el país contratante por medio de tribunales arbitrales, sin tener que usar los nacionales. ${ }^{27}$

Estados Unidos ha creado una amplia red de acuerdos internacionales de distinta índole para regular la inversión extranjera, pero nos remitiremos en el presente trabajo a los BIT y los TLC.

\section{EL MODELO ESTADOUNIDENSE DE BIT}

La diferencia entre un BIT y un TLC es que, mientras el primero se limita a regular la inversión extranjera, este último es un instrumento mucho más complejo que eslabona, junto con las libertades para la IE, una serie de normas que en su conjunto crean las condiciones perfectas para la entrada, instalación y funcionamiento de las ET; no sólo haciendo alusión a la apertura comercial, sino a las reglas de protección de propiedad intelectual, las oportunidades que se les abren de incursionar en las compras del sector público y servicios, etcétera.

Los denominados tratados bilaterales de inversión son un instrumento bilateral que surgió hace varias décadas, pero que fue hasta después de 2000 cuando se incrementó su uso de una forma nunca antes vista. ${ }^{28}$

Hay dos tipos básicos de BITs, el clásico europeo y el estadounidense. El primero es más acotado y más balanceado entre promoción y protección de la inversión, mientras el segundo se enfoca primordialmente en la protección con medidas más estrictas. ${ }^{29}$ Ambos en su contenido incluyen las

27 Trade Compliance Center, "Bilateral Investment Treaties", 21 de agosto de 2017. Disponible en: /http://tcc.export.gov/Trade_Agreements/All_Trade_Agreements/exp_002699.asp.

28 Los BIT pasaron, de menos de 400 antes de los años noventa a más de 2,000 al principio del siglo XXI, de acuerdo con las cifras de la UNCTAD, en 2005 ya se habían firmado 2,392. Además, ya entrada la década de los noventa se registraron cambios en las legislaciones de más de sesenta Estados en materia de IE, de los que el 94\% estaban encaminadas a favorecerla. UNCTAD, World Investment Report 2005, Nueva York-Ginebra, ONU, 2005, pp. 20-22.

29 Algunos mecanismos usados en el modelo europeo de BIT para promoción de la IE es ofrecer incentivos condicionados a ciertos requisitos de desempeño, intercambiar información y facilitar los trámites. 
cláusulas de trato nacional y nación más favorecida para inversiones establecidas, compensación por expropiación, derecho de libre transferencia, resolución de disputas Estado-Estado y en algunos inversionista-Estado, porque esta fórmula es más característica del modelo estadounidense. Mientras el modelo de EE UU incorpora aspectos como la prohibición de expropiación como de cualquier medida equivalente y de los requisitos de desempeño, el trato nacional y de nación más favorecida con respecto a los derechos de pre-establecimiento, entre otros aspectos innovadores. ${ }^{30}$ Para efectos de este trabajo nos centraremos en el modelo estadounidense de BIT.

Parafraseando la definición disponible en la página electrónica del Trade Compliance Center, los BIT son acuerdos bilaterales encargados de promover y proteger las inversiones reciprocas de los países y para el gobierno de EE UU, un tratado bilateral de inversión tiene por objeto garantizar que los inversionistas estadounidenses reciban el trato de nación más favorecida o trato nacional (lo que sea mejor) en el país signatario. Se protege a los inversionistas estadounidenses contra los requisitos de desempeño, las restricciones a las transferencias y contra la expropiación arbitraria. También los BIT, establecen los procedimientos para la solución de controversias y, por ende, proporcionan un entorno más abierto y seguro para la inversión, promoviendo el desarrollo del sector privado. ${ }^{31}$

En 2008 se concluyeron 58 nuevos BIT, de los cuales en 46 participaron Estados en desarrollo y en 38, países desarrollados; pero sólo trece fueron entre países en desarrollo. El número total de este tipo de acuerdos para 2017 superó los tres mil. ${ }^{32}$ Esto nos muestra que es un instrumento ampliamente usado en los últimos años, donde Estados Unidos tiene un gran dinamismo. Aunque también algunos han sido denunciados por países en desarrollo, cuestionando sus efectos negativos para el desarrollo econó-

30 Vandevelde, Kenneth, U.S. International Investment Agreements, Nueva York, Oxford University Press, 2009, pp. 19 y 20.

31 La Oficina del Representante Comercial de Estados Unidos y el Departamento de Estado, llevan a cabo conjuntamente las negociaciones de los BIT, con la asistencia del Departamento de Comercio y el Tesoro. El potencial BIT tiene que recibir el consejo y consentimiento del Senado antes de ser ratificado y entrar en vigor. Así, estos estarán en vigor durante diez años y seguirán a menos que una parte los denuncie con una notificación por escrito con un año de antelación a la otra parte para requerir su terminación. Trade Compliance Center, op. cit.

32 UNTAD, World Investment Report 2018, cit., p. 32. 
Esta revista forma parte del acervo de la Biblioteca Jurídica Virtual del Instituto de Investigaciones Jurídicas de la UNAM

mico y su escasa compatibilidad con las políticas nacionales, ejemplo de ello son Bolivia y Ecuador. ${ }^{33}$

En el desarrollo de estas negociaciones ha participado de forma destacada EE UU, con 39 BIT en vigor y seis en espera de ratificación, todos con países en desarrollo, y de los cuales nueve son con Estados latinoamericanos. ${ }^{34}$ Asimismo se han firmado otros seis en espera de ser ratificados, entre los cuales figuran uno con El Salvador, otro con Haití y el último con Nicaragua.

El gobierno estadounidense establece que los BIT tienen como fundamento proteger sus inversiones en el exterior, principalmente en los países donde los derechos de los inversionistas no están ya protegidos por otros acuerdos y sus objetivos son:

- Fomentar la adopción de políticas nacionales orientadas al mercado, que den un tratamiento de la inversión privada de manera abierta, transparente y no discriminatoria.

- Apoyar el desarrollo de las normas del derecho internacional en consonancia con estos objetivos.

Para cumplir con estos objetivos se ofrecen los seis lineamientos básicos que ya se mencionaron previamente en las cláusulas de los acuerdos de IE.

De forma general, este tipo de tratados cubren varios puntos esenciales, que van desde el ámbito de aplicación hasta la resolución de controversias, en donde debe remarcarse que, pese a que existen excepciones, en lo general, comparten una misma estructura.

El primer punto en los BIT es el referente al ámbito de aplicación, que alude tanto a las partes contratantes como a sus respectivas inversiones, por lo que se enuncia una definición de inversión, en donde prevalecen dos fórmulas: la más amplia que estipula qué se entenderá por "inversión" a toda clase de activos tales como bienes muebles o inmuebles, acciones, derechos e intereses de toda naturaleza, incluyendo derechos de propiedad; y la más delimitada, que se remite a una lista de todos los aspectos que pue-

33 Sólo en 2008 Ecuador denunció 9 BIT.

34 Los nueve países latinoamericanos con los que EE UU tiene un BIT en vigor son: Argentina, Bolivia, Ecuador, Granada, Honduras, Jamaica, Panamá, Trinidad y Tobago, y Uruguay. Ver Trade Compliance Center, op. cit. 
den considerarse como inversión. ${ }^{35}$ También se incluye una definición de "inversionista", donde se agrupa de forma general a los nacionales, ya sean personas físicas o morales. ${ }^{36}$

La apertura sectorial en los BIT y TLC suscritos por EE UU se aplica a todos los sectores, a excepción de las reservas, aunque existen casos donde algunos países no hacen reservas, como el Tratado de Libre Comercio de Estados Unidos con Centroamérica y República Dominicana (CAFTA-DR, por sus siglas en inglés); ${ }^{37}$ así, éstos instrumentos incluyen una lista de sectores y actividades económicas explícitamente excluidas del acuerdo.

Cabe señalar que, aunque la mayoría de estos acuerdos no son retroactivos, hay algunos pocos que se aplican no sólo a las inversiones que se lleven a cabo a partir de la firma del acuerdo, sino a las ya existentes antes del mismo.

En lo concerniente a la aplicación en el tiempo, en su mayoría este tipo de tratados prevé que entren en vigor un mes después de que se depositen los instrumentos de ratificación por las partes y se mantengan así por un período inicial de diez años, factibles de extenderse por mutuo acuerdo de las partes. ${ }^{38}$

En el tratamiento y protección de las inversiones, punto neurálgico de los BIT, anteriormente se limitaba a brindar un trato justo y equitativo a las inversiones de conformidad con los principios del derecho internacional o se remitía a las legislaciones nacionales. ${ }^{39}$ Ahora se complementa o se susti-

35 La fórmula más utilizada en los BIT recientes es la que busca incorporar toda clase de inversión, como son los nuevos instrumentos financieros o las nuevas formas de transacción. Ejemplo de ello son los suscritos por EE UU con Argentina (1991), Bolivia (1998), Ecuador (1993), El Salvador (1999) y Honduras (1995). Mientras los BIT de la fórmula más restringida son los de EE UU con Granada (1986) y Haití (1983).

36 Normalmente la definición de "nacional" ésta sujeta a la legislación interna de cada parte, y pueden prevalecer distintas formas para determinarla, principalmente en el caso de las personas jurídicas, como el asiento o lugar de constitución, el control directo o indirecto de la empresa, o una combinación entre éstos.

37 Mientras los países centroamericanos no reservaron ningún sector, EE UU sí reservó los siguientes sectores: telecomunicaciones, servicios sociales, minorías sociales y económicas, transporte marítimo, trato preferencial en otros acuerdos internacionales y trato preferencial en relación con los sectores de aviación, pesca y asuntos marítimos.

38 Kaplan, Marcos y Manrique, Irma, Regulación de los flujos financieros internacionales, México, UNAM, 2000, pp. 108 y 109.

39 En muchos BIT firmados por países en desarrollo, particularmente latinoamericanos, se establece que las inversiones se admitirán “de acuerdo con la legislación vigente en la parte 
tuye con los principios de trato nacional, de nación más favorecida y un nivel mínimo de trato, como parte de la no discriminación.

La no discriminación prohíbe básicamente el trato desigual en contra de las inversiones que realicen los inversionistas de la otra parte a través de los tres principios antes mencionados. La cláusula de trato nacional establece el compromiso de otorgar a los inversionistas e inversiones de la otra parte un trato no menos favorable que el dado a las inversiones e inversionistas nacionales. El principio de nación más favorecida consiste en hacer extensivos para la otra parte del acuerdo todos los beneficios que se brinden a las inversiones de un tercer Estado. ${ }^{40}$ Finalmente, el nivel mínimo de trato rescata al trato justo y equitativo; para el que no existe una definición por lo que se liga con los principios del derecho internacional consuetudinario para su interpretación. En los BIT firmados por Estados Unidos este precepto se combina con el de seguridad y protección plenas. ${ }^{41}$

Otro aspecto de los BIT es el prohibir los requisitos de desempeño, restringiendo una práctica que había sido utilizado con frecuencia por los países en desarrollo para vincular a las inversiones con el desarrollo nacional, es decir, que impide imponer o hacer cumplir algún tipo de condición para su establecimiento, la adquisición, la expansión, la dirección, la explotación o el funcionamiento de una inversión. ${ }^{42}$

Un punto más es el relacionado con la libre transferencia, que establece la libertad plena de la otra parte para transferir todo tipo de fondos relacionados con las inversiones, donde casi siempre se incorpora una lista, sin embargo, en algunos tratados se remarca que tal lista no limita el tipo de pagos a transferir. De igual forma se menciona que las transferencias deberán ser en moneda convertible y sin demora.

receptora”. Zabludovsky, Jaime y Gómez Lora, Sergio, Principales retos de la negociación de un tratado de libre comercio con Estados Unidos: disciplinas en materia de inversión, Washington D.C., INTAL-BID, 2005, p. 5.

40 En la mayoría de estos tratados se prevé una serie de excepciones explícitas, principalmente en lo que se refiere a las cláusulas de trato nacional y nación más favorecida con respecto a los privilegios dados a terceros Estados como resultado de cualquier proceso de integración o de cualquier tratado internacional en materia tributaria.

41 Kaplan, Marcos y Manrique, Irma, op. cit., p. 110.

42 El BIT entre EU UU y Nicaragua fue de los primeros en prohibir totalmente los requisitos de desempeño, seguido por otros como los que se tiene con Honduras, El Salvador y Uruguay que también siguieron esta tónica. 
Esta libertad de transferencia es una contradicción, puesto que los BIT en el preámbulo declaran fomentar las inversiones de largo plazo, pero no establecen normatividad alguna para el tipo de inversión, el tiempo de permanencia de la misma, etcétera. Así que no existe, ni en la práctica ni en la teoría, una real diferenciación de las inversiones a largo plazo de las especulativas, lo que permite que las prácticas de los capitales golondrinos aumenten, al igual que el riesgo de crisis financieras.

En lo que corresponde a la expropiación, ésta queda prohibida, salvo algunas excepciones en determinadas circunstancias, como el estar relacionadas con el bienestar público, con apego a la legislación nacional y con un inmediato y justo pago de indemnización. La utilidad pública no puede estar sustentada en intereses de grupo; más, no existe una definición precisa y a veces se sustituye o complementa con otras expresiones como interés nacional, seguridad nacional o interés social, entre otras. Algunos BIT llevan esto al extremo y permiten reclamar indemnización, no sólo por perdidas en una inversión en operación, sino por oportunidades no logradas de ganancia en relación a una inversión aún en proyecto. ${ }^{43}$

En lo que alude a la solución de controversias, existe el nivel más común, que se refiere a los conflictos entre los Estados parte, para lo que se creará un tribunal ad hoc, al cual se someterá la controversia, siempre y cuando se haya intentado la negociación sin resultados satisfactorios. ${ }^{44} \mathrm{El}$ tiempo que se concede para la resolución varia, mientras que para el pago de la indemnización se usa generalmente la expresión de "al valor del mercado" o "al justo valor del mercado" y que el pago sea transferible y realizado sin demora. Como nivel innovador, se incluyen las controversias entre un Estado parte y un inversionista (de la otra parte); que de igual manera serán dirimidas en un tribunal ad hoc.

En la generalidad de los casos se remite al arbitraje en el marco del Centro Internacional de Arreglo de Diferencias Relativas a Inversiones (CIADI), o el de su mecanismo complementario, cuando alguna de las partes no sea miembro del mismo. Actualmente, se ha extendido a formas alternativas de arbitraje, como el de la Comisión de las Naciones Unidas

43 Calderón Salazar, Jorge A. (coord.), México en un mundo global, México, Friedrich Ebert Stiftung, 2001, p. 216.

44 A este punto por lo general se agrega una lista con los detalles del procedimiento para formar el tribunal, y para que legislación se aplicará, casi siempre se recurre a lo dispuesto en el tratado o al derecho internacional. 
Esta revista forma parte del acervo de la Biblioteca Jurídica Virtual del Instituto de Investigaciones Jurídicas de la UNAM

sobre Derecho Mercantil Internacional (CNUDMI), o en el caso de algunos de ellos, firmados por EE UU, se remiten a la Cámara Internacional de Comercio (CIC)..$^{45}$

Este apartado sobre controversias entre un Estado y un inversionista da facilidades a los inversionistas para poder demandar y enjuiciar a un Estado anfitrión en igualdad de condiciones a nivel internacional, sin la obligación de agotar en primera instancia los mecanismos jurídicos internos. Como señala Jorge A. Calderón, no existe la contraparte donde el Estado anfitrión pueda demandar a un inversionista extranjero por malas prácticas. ${ }^{46}$

En pocas palabras, este tipo de tratados están orientados a favorecer el flujo de inversiones hacia los países en desarrollo por parte de EE UU que, como exportador de inversiones, suele pactarlos con países receptores de inversiones; pero, como subraya Antonio Belaurde Moreyra, esta asimetría no la refleja el contenido del acuerdo, ya que están concebidos en pie de igualdad. ${ }^{47}$ Además, en el caso de Latinoamérica, EE UU resguarda su papel como principal inversionista.

Los BIT por mucho tiempo fueron los principales instrumentos en la materia utilizados por Estados Unidos y, por tanto, con los parámetros más extensos para la protección y promoción de las inversiones externas, hasta que se incluyeron sus regulaciones como parte de los TLC, que no sólo han igualado su contenido, sino que lo han superado.

\section{DEL TLCAN AL UMSCA}

El UMSCA, firmado el 30 de noviembre de 2018, es el mejor referente para comprender la estrategia actual de la administración Trump para la IE por medio de los TLC; pues, no sólo demuestra la forma en que un país poco desarrollado puede negociar con la primera potencia mundial, sino también los contenidos que Estados Unidos está manejando como parte de su agenda en esta materia. Este representa una señal diáfana respecto a la intención de la primera potencia económica de solicitar, a cambio de la apertura de su mercado de bienes, la inclusión de estas disciplinas, además de algunas otras,

45 Kaplan, Marcos y Manrique, Irma, op. cit., p. 114.

46 Calderón Salazar, Jorge A., op. cit., p. 218.

47 Belaurde Moreyra, Antonio, "Enfoque histórico de la promoción y protección de las inversiones”, Revista del Foro, Lima, año XXIX, enero-junio de 1991, p. 227. 
en toda negociación de libre comercio, principalmente cuando se trata de economías en desarrollo como las de sus vecinos del sur. ${ }^{48}$

Se debe señalar que el USMCA tiene como precedente el TLCAN, el cual entró en vigor el 1o. de enero de 1994 y fue el primer acuerdo comercial en incluir una amplia regulación para la inversión extranjera. Es preciso reconocer el carácter único del TLCAN como que crea una nueva generación de TLC; no sólo por el hecho de conjuntar miembros con grados tan heterogéneos de desarrollo en condiciones de igualdad, como México por una parte y Estados Unidos junto con Canadá, por la otra. Sino por ser un tratado que rebasa por mucho su carácter netamente comercial para conjuntar una plétora de disciplinas en diversas materias relacionadas con el comercio, tales como, servicios, propiedad intelectual y, por supuesto, inversiones; que es uno de los aspectos más relevantes dentro del acuerdo y con amplias repercusiones en la configuración jurídica y económica de los miembros, principalmente de México. ${ }^{49}$

El TLCAN no puede ser considerado como un tratado esencialmente comercial, dado que es también un tratado de libre inversión, como enfatiza el especialista británico, E.V.K. FitzGerald: "la implicación más importante del NAFTA para México y América Latina es la referida al régimen de inversión extranjera"; ${ }^{50}$ esto bajo el sustento del énfasis que se le brinda a éste aspecto al introducir una amplia legislación internacional en la materia; en suma al avance que significa, puesto que en el comercio entre los miembros ya se había liberalizado, mientras que el tema de inversiones

48 Los TLC de Estados Unidos con Canadá y Australia (2004), por ser socios desarrollados con regímenes modernos de inversión, no incluyen un mecanismo de resolución de disputas inversionista-Estado, como tampoco lo incluyen los firmados con Israel, Bahrein y Jordania. En el caso de Israel, aparte de no ser un país en desarrollo el acuerdo data de mucho tiempo (1985) y es menos detallado y abarcador que los actuales. En los casos de Bahrein y Jordania su ausencia se explica por la existencia de BIT previos, firmados en 1999 y 1997, respectivamente. Esto evidencia la intención de EE UU de proteger su inversión principalmente en los países en desarrollo.

49 El único acuerdo previo de libre comercio con regulación para la IE era el Acuerdo de Libre Comercio Canadá-Estados Unidos (ALCCEU) de 1988, asimilado por el TLCAN, que, si bien contenía un capítulo similar al de éste en materia de inversión, está lejos de ser tan comprensivo, extenso y riguroso.

50 Fitzgerald, E.V. K., “Trade, Investment and NAFTA: The Economics of Neighbourhood”, en Bulmer-Thomas, Víctor y Dunkerley, James (eds.), The United States and Latin America:The New Agenda, Cambridge-Massachusetts, David Rockefeller Center for Latin American Studies, Harvard University-Institute of Latin American Studies, University of London, 1999, p. 115. 
nunca se había tratado formalmente, ya que siempre había existido un desacuerdo sobre el contenido de un posible acuerdo exclusivo para la inversión. El capítulo XI del TLCAN, referente a las inversiones, y punto medular del tratado, en su momento fue uno de los más amplios en la materia, o el más extenso si tomamos en cuenta que es un TLC.${ }^{51}$ No hay que perder de vista que el TLCAN trascendió al convertirse en el precedente por excelencia para los subsecuentes TLC que se han y se están firmando no sólo en el hemisferio occidental, sino en el mundo, principalmente en los que Estados Unidos participa.

ElTLCAN se diferencia de los acuerdos clásicos de libre comercio por su capítulo sobre IE y por incluir un mecanismo de solución de controversias inversionista-Estado que, como señala Bernardo Sepúlveda, vulnera la jurisdicción nacional al delegar facultades privativas del Estado a una autoridad supranacional, rompiendo definitivamente con los principios defendidos por la Cláusula Calvo y la Carta de Derechos y Deberes Económicos de los Estados. ${ }^{52}$ Esto implicó expandir el mecanismo a sus socios fronterizos y al mismo tiempo crear un modelo de acuerdo para firmar con países en desarrollo. ${ }^{53}$

La firma delTLCAN tuvo como uno de sus principales pilares la regulación de la IE; desde el punto de vista de Canadá y México esto serviría como imán para la atracción de mayores flujos de ese tipo de capital, mientras que para EE UU representaba una oportunidad de expandir y reforzar su presencia económica en sectores antes vetados a sus ET. ${ }^{54}$ En esta lógica, se evidencía que este capítulo repercutió principalmente en $\mathrm{México}^{55}$ si se considera que

51 El precursor más cercano del capítulo XI del TLCAN es el capítulo sobre la misma materia que se incluyó en el Acuerdo de Libre Comercio Canadá-Estados Unidos (ALCCEU), el cual también contiene disposiciones para la protección y liberalización de las inversiones; sin embargo, no incluía el mecanismo de solución de disputas inversionista-Estado.

52 Sepúlveda Amor, Bernardo, "Derecho internacional y soberanía nacional: el TLC y las reivindicaciones de la jurisdicción mexicana”, en Madrid Hurtado, Miguel de la et al., El papel del derecho internacional en América. La soberanía nacional en la era de la integración regional, México, UNAM-The American Society of International Law, 1997, p. 112.

53 Vega Cánovas, Gustavo et al., México, Estados Unidos y Canadá: resolución de controversias en la era post Tratado de Libre Comercio de América del Norte UNAM-COLMEX, México, 2005, p. XIX.

54 Ibarra, Marilyn y Koncz, Jennifer, "Direct Investment Positions for 2008” U.S. Bureau of Economic Analysis, Operations of Multinational Companies. U.S. Direct Investment Abroad, pp. 20 y 21.

55 La política de México hacia la IE se había caracterizado por ser restrictiva y selectiva, sin embargo, esto empezó a modificarse hacia la liberalización a partir de la administración de Miguel de la Madrid y ampliada con la de Carlos Salinas de Gortari. 
las reglas en la misma materia tanto en Estados Unidos como en Canadás6 ya eran flexibles.

ElTLCAN se inspira en el modelo de BIT estadounidense, así como el Acuerdo de Libre Comercio entre Canadá y EE UU. Su contenido se estructura de forma muy similar, puesto que tiene como puntos rectores la apertura sectorial, el trato a la inversión, los requisitos de desempeño, la transferencia, la expropiación y la solución de controversias. No obstante, hay muchos puntos en lo que el capítulo XI es innovador al compararse con los acuerdos previos de IE porque, esencialmente, vincula la regulación de las inversiones con el comercio y otros sectores como la propiedad intelectual e incluye un sistema de resolución de controversias entre el inversionista y el país. Asimismo, el TLCAN incluye la protección pre-establecimiento, es decir, que se aplica a las inversiones ya existentes antes de que el acuerdo entrara en vigor. Esto explica el origen del "modelo TLCAN" como cimiento para otros acuerdos y para el propio AMI. ${ }^{57}$

Desde que entró en vigor elTLCAN, y gracias a la misma experiencia estadounidense en la firma y aplicación de acuerdos en materia de inversión, su normatividad internacional en este aspecto ha evolucionado, y esto se refleja en el contenido del capítulo del UMSCA, el cual ya los incorpora, aunque sigue la misma estructura de su predecesor.

Dejando a un lado toda la expectativa, sincretismo y opacidad que marcaron a las negociaciones del UMSCA en relación con la regulación de la inversión extranjera, se le da continuidad al modelo de BIT estadounidense y sigue acorde a los lineamientos marcados por las administraciones anteriores. El capítulo XIV del UMSCA, denominado por el Presidente Trump como el "más moderno, actualizado y equilibrado acuerdo", a la luz delTLCAN, tiene las siguientes características:

56 Canadá cambió su enfoque hacia la IE durante los años ochenta. En 1985 la Foreing Investment Review Agency (Agencia Revisora de la IE) de Canadá, la cual se encargaba de revisar la mayor parte de la IE a fin de comprobar su beneficio a la nación, fue remplazada por la Investment Canada con el fin primordial de trabajar en la promoción a la IE, con un cambio en el procedimiento de revisión que lo hiciera más flexible y racional. Graham, Edward M., y Wilkie, Cristopher, "Acuerdos económicos regionales y firmas multinacionales, las disposiciones en materia de inversión en el TLCAN (NAFTA)”, ARS IURIS, México, núm. 21, 1999 , p. 38.

57 Melgar Manzanilla, P. y Quintero Sánchez, A., "The Impact of NAFTA Chapter XI on México”, Opción, año 24, núm. 14, 2018, pp. 1663 y 1664. 
- No hay un cambio radical en las disposiciones, se incluyen ciertas precisiones conceptuales emanadas de la experiencia del TLCAN, principalmente para clarificar conceptos y evitar lagunas jurídicas.

- Incluye a las empresas paraestatales, ya que en el TLCAN estas no eran objeto de las regulaciones del capítulo XI, en el nuevo acuerdo deben respetar los principios de trato nacional y nación más favorecida, así como las demás cláusulas, e igualmente pueden ser demandadas en un tribunal arbitral. Esto reproduce los lineamientos que ya había negociado Estados Unidos en el TPP. ${ }^{58}$

- Se limita y sofistica el mecanismo de solución de controversias inversionista-Estado, esto como respuesta a los abusos presentados en el TLCAN por demandas infundadas y procedimientos altamente costosos. ${ }^{59}$ Para los inversionistas en general, se limita la posibilidad a acudir a este mecanismo, sólo podrán hacerlo por cuestiones relacionadas con trato nacional, trato de nación más favorecida o expropiación directa; las demás violaciones solo podrán dirimirse en el procedimiento Estado-Estado. Mientras que para los inversionistas en sectores estratégicos, se conserva el mecanismo inversionista- Estado tradicional para todas las disposiciones. Los sectores estratégicos son únicamente energía, generación de electricidad, transporte, telecomunicaciones e infraestructura. Se debe enfatizar el hecho de que el sistema de solución de controversias inversionista-Estado ha sido de las partes más criticadas en los acuerdos de inversión, ya que una empresa privada puede demandar al Estado en pie de igualdad en un tribunal arbitral ad hoc, eludiendo a las leyes y a los tribunales nacionales del país demandado.

- En el caso de México, se abren todos los sectores que habían quedado excluidos parcial o totalmente en el capítulo XIX delTLCAN, para ser susceptibles de inversión extranjera.

- Canadá se reservó de este capítulo. ${ }^{60}$

58 Quintero Sánchez, Adelina, "Retos y disyuntivas del proceso de negociación y entrada en vigor del Acuerdo de Asociación Transpacífico (ATP): un estudio crítico de caso”, en Velázquez Elizarrarás, Juan Carlos, El estudio interactivo de los tratados internacionales en México, México, UNAM, 2017, pp. 299-302.

59 Ibidem, pp. 312 y 313.

60 Acuerdo Estados Unidos-México-Canadá (USMCA), capítulo XIV, 2017. 
Lo negociado en el UMSCA refleja que la administración de Trump conserva el mismo interés de proteccionismo hacia sus empresas que operen en México y Canadá, por lo que la regulación en materia de inversión extranjera lejos de modificarse se ha endurecido y extendido a nuevos sectores antes vetados para la inversión en México y a nuevos actores, haciendo referencia a las empresas paraestatales que gozaban de fuero ante las posibles demandas por parte de inversionistas foráneos.

Más allá del USMCA hay otras iniciativas y acciones relacionadas con la regulación de la inversión extranjera por parte del gobierno actual de EE UU, que se deben considerar.

En primera instancia, la orden ejecutiva por la que el presidente Trump retira a su país del TPP, el 23 de enero de 2017, se podría considerar un retroceso en el objetivo de ampliar su regulación internacional hacia la IE, principalmente en una región estratégica, que es el sudeste asiático, donde está avanzando China con la firma de distintos instrumentos para la inversión extranjera que siguen su propio modelo e interés nacional. No obstante, no se puede soslayar el trasfondo político que matizó la decisión y las últimas declaraciones del gobierno estadounidense que al parecer está reconsiderando formar parte del acuerdo. ${ }^{61}$

La oposición que ha mostrado el primer mandatario estadounidense hacia el comercio y la inversión externa, son parte de un discurso neoproteccionista, para sustentar el andamiaje ideológico que lo llevó al puesto que ostenta. No obstante, como señalan, Adam S. Chilton, Helen V. Milner y Dustin Tingley, una cosa es la retórica discursiva y las cuestiones que se manejan en los medios masivos de comunicación y otra, son las políticas y acuerdos que se firman en las diferentes materias; como sucede en relación con el comercio y la inversión. ${ }^{62}$

Por otro parte, se debe considerar que Estados Unidos no ha denunciado otros acuerdos de libre comercio ni ha siquiera intentado sustraerse de sus acuerdos bilaterales de inversión, siendo uno de los países con el mayor número de este tipo de instrumentos. Actualmente tiene en vigor acuerdos con Albania, Argentina, Armenia, Azerbaijan, Bahrein,

61 Adelina Quintero, op. cit., pp. 296 y 297.

62 Chilton, Adam S. et al., "Reciprocity and Public Opposition to Foreign Direct Investment”, British Journal of Political Science, 2017, p. 13. 
Bangladesh, Bolivia, Bulgaria, Camerún, República Democrática del Congo, Croacia, República Checa, Ecuador, Egipto, Estonia, Georgia, Granada, Honduras, Jamaica, Jordania, Kazakistan, Kirguistán, Latvia, Lituania, Moldávia, Mongolia, Marruecos, Mozambique, Panamá, Polonia, Rumania, Ruanda, Senegal, Eslovaquia, Siri Lanka, Trinidad y Tobago, Túnez, Turquía, Ucrania y Uruguay. ${ }^{63}$

Asimismo, se ha dado seguimiento a los acuerdos marco para el comercio y la inversión (TIFA, por sus siglas en inglés), que han firmado con incontables países de África, Medio Oriente y Asia. Los TIFA son acuerdos que sólo establecen un marco de cooperación entre las partes contratantes y esa cooperación frecuentemente toma la forma de un marco institucional para dar seguimiento a las reglas de inversión e identificar los plazos requeridos para lanzar las futuras negociaciones para la liberalización y protección de la inversión. La meta a largo plazo de los TIFA es que cristalicen en acuerdos más sustantivos, como los BIT. ${ }^{64}$ En el caso de África, de igual manera se cuenta con el Acta Africana de Crecimiento y Oportunidad (AGOA, por sus siglas en inglés), la cual tiene como objetivo fomentar oportunidades de comercio e inversión en los países de África Subsahariana. ${ }^{65}$

Por último, no se debe olvidar que Estados Unidos es el país con más tratados de doble imposición (DTT, por sus siglas en inglés); que indirectamente forman parte de su esquema internacional de regulación para la inversión extranjera, al estar enfocados en evitar que a sus empresas transnacionales se les duplique el cobro de impuestos y con esto igualmente se busca que los impuestos queden en Estados Unidos y no se paguen en los países donde tienen inversiones sustanciales. ${ }^{66}$

63 Los BIT con Bolivia y Ecuador han sido denunciados por los respectivos países latinoamericanos, por lo que el primero ya no está en vigor y el segundo termina en 2018. Office of the United States Trade Representative, "Bilateral Investment Treaties Currently in Force (from the Trade Compliance Center)", 18 de agosto de 2017. Disponible en: https://tcc.export.gov/Trade_Agreements/Bilateral_Investment_Treaties/index.asp.

64 Office of the United States Trade Representative, "Trade \& Investment Framework Agreements", 25 de agosto de 2017. Disponible en: http://www.ustr.gov/trade-agreements/ trade-investment-framework-agreements.

65 Office of the United States Trade Representative, "African Growth and Opportunity Act (AGOA)”, 17 de octubre de 2017. Disponible en: https: / / ustr.gov/issue-areas/trade-development/preference-programs / african-growth-and-opportunity-act-agoa.

66 EE UU es el país con mayor número de DTT firmados con 153, seguido por Reino Unido con 151 y Francia con 133. Entre los países en desarrollo sobresale China con 99, la Repú- 


\section{CONCLUSIONES}

La política que ha caracterizado a EE UU en materia de IE responde a sus estrategias de desarrollo nacional para garantizar su hegemonía económica mundial y sustentar su rol como principal emisor y receptor de estos flujos, así como para ser la casa matriz de un vasto número de las principales ET en el mundo. Este objetivo no se ha modificado en forma substancial desde el término de la SGM hasta la fecha, sin importar los cambios de administraciones.

De ahí que en las últimas décadas EE UU es uno de los países más activos en la firma no sólo de BIT y TLC, que incluyen un capítulo para la inversión;sino de otros instrumentos que incorporan esta apertura y protección a sus ET junto con sus inversiones, como los acuerdos marco para el comercio y la inversión que ha firmado con innumerables países en desarrollo en todos los continentes, o los tratados de doble imposición, que utiliza para proteger a sus empresas del doble cobro de impuestos.

Asimismo, es uno de los principales impulsores de la mayor sofisticación y endurecimiento de las normas jurídicas internacionales a favor de la protección de la IE, sin menoscabar el hecho de ser el artífice de la formula comercio-inversión, siendo elTLCAN pionero en esta categoría. Hecho que responde a una estrategia más sofisticada que consiste en, por medio de vender las potenciales bondades del comercio, condicionar la inclusión del tema de la IE, tal como las recientes negociaciones del UMSCA lo demostraron fehacientemente. Cabe señalar el hecho de que las contrapartes en todos estos acuerdos son, en esencia, países en desarrollo, en los cuales históricamente ha buscado invertir para obtener materias primas, al tiempo que ha intentado imponer las más amplias garantías para sus empresas.

Actualmente, con el gobierno del presidente Donald Trump se reafirma la misma tendencia con la firma del UMSCA y el seguimiento de sus demás instrumentos internacionales en materia de inversión. En general, las acciones y políticas internacionales en torno a la inversión por parte de dicha administración, aunque más neoproteccionistas, responden al devenir

blica de Corea con 81 e India con 79. De acuerdo con la UNCTAD, Estados Unidos cuenta, aparte de sus BIT, con otros 69 acuerdos con normas para la inversión extranjera. UNCTAD, Investment Policy Hub, International Investment Agreements Navigator, Nueva York-Ginebra, ONU, 7 de enero de 2018. Disponible en: https: / / investmentpolicyhub.unctad.org/IIA. 
Esta revista forma parte del acervo de la Biblioteca Jurídica Virtual del Instituto de Investigaciones Jurídicas de la UNAM

DOI: http://dx_doi.org/10.22201/iij_24.487872e_2020.20.14490

histórico del país en la materia y a su objetivo primario de proteger a sus empresas en el exterior, principalmente cuando se instalan en países en desarrollo. Quizá podría marcar un parteaguas y un cambio en este sentido la firma de la Asociación Trasatlántica para el Comercio y la Inversión, entre la Unión Europea y EE UU, al considerar que la primera sigue siendo el ente más representativo en la exportación de capitales en el mundo y no concilia intereses con varios principios para la inversión negociados por EE UU, como el referente a la solución de controversias inversionista- Estado. No obstante, es por esa razón, entre otras, que las negociaciones se estancaron después de ser lanzadas por la administración de Obama, principalmente con la llegada de Trump.

\section{BIBLIOGRAFÍA}

Álvarez ÁvilA, Gabriela, "Las características del arbitraje del CIADI", en VelásqueZ ElizarRarás, Juan Carlos (comp.), El derecho internacional público y privado a través de los debates teóricos actuales en las Universidades de México y el extranjero, México, UNAM, 2005.

BAREFoOt, Kevin B. y Raymond, J. Mataloni Jr., "U.S. Multinational Companies", U.S. Bureau of Economic Analysis, Operations of Multinational Companies. U.S. Direct Investment Abroad, 2008.

Belaurde Moreyra, Antonio, "Enfoque histórico de la promoción y protección de las inversiones”, Revista del Foro, Lima, año XXIX, enero-junio de 1991.

Calderón Salazar, Jorge A., (coord.), México en un mundo global, México, Friedrich Ebert Stiftung, 2001.

Contreras García, Joaquín, "Algunas consideraciones sobre la protección a la IED a la luz del derecho internacional privado", Jurídica, México, núm. 24, 1995.

CheCKLey, Juan Carlos et al., "La inversión extranjera y los convenios MIGA y OPIC”, Revista del Foro, Lima, año XXIX, enero-junio de 1991.

Chilton, Adam S. et al., "Reciprocity and Public Opposition to Foreign Direct Investment”, British Journal of Political Science, 2017.

DÁvila Aldas, Francisco, "América Latina y la globalización”, Revista de Relaciones Internacionales, México, núms. 101 y 102, mayo-diciembre de 2008. 
Esta revista forma parte del acervo de la Biblioteca Jurídica Virtual del Instituto de Investigaciones Jurídicas de la UNAM

FitzGerald, E.V. K., "Trade, Investment and NAFTA: The Economics of Neighbourhood", en Bulmer-Thomas, Víctor y Dunkerley, James (eds.), The United States and Latin America: The New Agenda, CambridgeMassachusetts, David Rockefeller Center for Latin American Studies, Harvard University-Institute of Latin American Studies, University of London, 1999.

“Global 2000: Las empresas más grandes del mundo de 2018”, Forbes, México, 7 de enero de 2018. Disponible en: https: / / www. forbes.com. mx/global2000-las-empresas-mas-grandes-del-mundo-de-2018/.

FUKUNARI, Kimura, Issues and Options for the Multilateral, Regional, and Bilateral Trade Policies of the United States and Japan, Conferencia en la Universidad de Michigan (Ann Arbor), 5 y 6 de octubre de 2000.

Graham, Edward M., y WiLKIE, Cristopher, “Acuerdos económicos regionales y firmas multinacionales, las disposiciones en materia de inversión en el TLCAN (NAFTA)", ARS IURIS, México, núm. 21, 1999.

GuTiÉRrEZ-HACES, Teresa y QuiNTERO, Adelina, "Hacia la construcción de un régimen internacional de protección a la inversión extranjera”, Norteamérica, México, vol. 11, núm. 2, 2016.

GuTIÉRREZ-HACES, Teresa, "Inversión extranjera directa en el TLCAN", Economía, México, vol. 1, núm. 3, 2004.

International Trade Administration, "Promoting Trade and Investment", 18 de abril de 2017. Disponible en: http: / trade.gov/promotingtrade/index.asp.

KAPLAN, Marcos y MANRIQUE, Irma, Regulación de los flujos financieros internacionales, México, UNAM, 2000.

Melgar Manzanilla, P. y Quintero Sánchez, A., "The Impact of NAFTA Chapter XI on México”, Opción, año 24, núm. 14, 2018.

NASSAR GUIER, Edgar, "La garantía internacional de inversiones”, Relaciones Internacionales, Costa Rica, 2a. época, 1994.

O'Brien, Thomas, The Century of U.S. Capitalism in Latin America, Nuevo Mexico, University of New Mexico Press, 1999.

Office of the United States Trade Representative, "African Growth and Opportunity Act (AGOA)", 17 de octubre de 2017. Disponible en: https: / / ustr.gov/issue-areas/trade-development/preference-programs/africangrowth-and-opportunity-act-agoa. 
Esta revista forma parte del acervo de la Biblioteca Jurídica Virtual del Instituto de Investigaciones Jurídicas de la UNAM

Office of the United States Trade Representative, "Bilateral Investment Treaties”, 8 de mayo de 2017. Disponible en: http: / / www. ustr.gov/ trade-agreements/bilateral-investment-treaties.

Office of the United States Trade Representative, "Bilateral Investment Treaties Currently in Force (from the Trade Compliance Center)", 18 de agosto de 2017. Disponible en: https://tcc.export.gov/Trade_Agreements/Bilateral_Investment_Treaties/index.asp.

Office of the United States Trade Representative, “Trade \& Investment Framework Agreements", 25 de agosto de 2017. Disponible en: http: / / www.ustr.gov/trade-agreements / trade-investment-framework-agreements.

QuinTERO SÁnCHEZ, Adelina, "Retos y disyuntivas del proceso de negociación y entrada en vigor del Acuerdo de Asociación Transpacífico (ATP): un estudio crítico de caso”, en VELÁzQUEZ Elizarrarás, Juan Carlos, El estudio interactivo de los tratados internacionales en México, México, UNAM, 2017.

RoETT, Riordan, "La política de los Estados Unidos frente a la integración continental", Contribuciones, año XVIII, núm. 3, julio-septiembre de 2001.

SAUVANT, Karl P. y ORTINO, Federico, Improving the International Investment Law and Policy Regime: Options for the Future, London, King's College, London, 2017.

SEPÚlVEDA AMOR, Bernardo, "Derecho internacional y soberanía nacional: el TLC y las reivindicaciones de la jurisdicción mexicana”, en MADRID HuRTADO, Miguel de la et al., El papel del derecho internacional en América. La soberanía nacional en la era de la integración regional, México, UNAMThe American Society of International Law, 1997.

Tolentino, Paz Estrella, "Transnational Rules for Transnational Corporations. What Next?", en MiCHIE, Jonathan y GRIEVE-SMITH, John (eds.), Global Instability: The Political Economy of World Governance, Londres, Universidad de Londres, 1999.

Trade Compliance Center, "Bilateral Investment Treaties", 21 de agosto de 2017. Disponible en: / http: / /tcc.export.gov/Trade_Agreements/All_ Trade_Agreements/exp_002699.asp.

UNCTAD, International Investment Rule-Making: Stocktaking, Challenges and the Way Forward, Nueva York-Ginebra, ONU, 2008. 
Esta revista forma parte del acervo de la Biblioteca Jurídica Virtual del Instituto de Investigaciones Jurídicas de la UNAM

UNCTAD, Investment Policy Hub, International Investment Agreements Navigator, Nueva York-Ginebra, ONU, 7 de enero de 2018. Disponible en: https: / / investmentpolicyhub.unctad.org/IIA.

UNCTAD, World Investment Report 2005, Nueva York-Ginebra, ONU, 2005.

UNCTAD, World Investment Report 2018, Nueva York-Ginebra, ONU, 2018. VAndeVelde, Kenneth, The First Bilateral Investment Treaties. U.S. Postwar Friendship, Commerce, and Navigation Treaties, EUA, Oxford University Press, 2017.

VANDEVELDE, Kenneth, U.S. International Investment Agreements, Nueva York, Oxford University Press, 2009.

Vega CÁnovas, Gustavo et al., México, Estados Unidos y Canadá: resolución de controversias en la era post Tratado de Libre Comercio de América del Norte UNAM-COLMEX, México, 2005.

Zabludovsky, Jaime y Gómez LORA, Sergio, Principales retos de la negociación de un tratado de libre comercio con Estados Unidos: disciplinas en materia de inversión, Washington DC, INTAL-BID, 2005. 